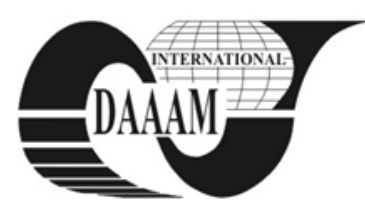

Annals of DAAAM for 2011 \& Proceedings of the 22nd International DAAAM Symposium, Volume 22, No. 1, ISSN 1726-9679 ISBN 978-3-901509-83-4, Editor B. Katalinic, Published by DAAAM International, Vienna, Austria, EU, 2011 Make Harmony between Technology and Nature, and Your Mind will Fly Free as a Bird Annals \& Proceedings of DAAAM International 2011

\title{
THE INFLUENCE OF VACUUM ON THE OCCURRENCE OF POROSITY DURING CASTING OF ALUMINUM ALLOYS
}

\author{
CVJETKO, I[gor]; BUDIC, I[van] \& NOVOSELOVIC, D[aniel]
}

\begin{abstract}
The paper examines the influence of vacuum on the occurrence of porosity during casting of aluminum alloys. Porosity belongs to one of the main factors regarding quality of the products in casting industry. Porosity cause casting defects, have negative influence on quality of casting and decrease usability of castings in respect of reduction of their tensile strength, material fatigue and impact resistance which influences directly density of the casting itself. Hydrogen as the only gas capable to solve in significant quantities in aluminum melt is the main factor influencing gas porosity.
\end{abstract}

Key words: casting defects, gas dissolution, porosity, influence of vacuum, aluminum alloys

\section{INTRODUCTION}

Porosity belongs to one of the main factors regarding quality of the products in casting industry. Porosity in some degree is always present, has bad influence on quality of the surface of the casting, its mechanical properties and resistance to corrosion. Hydrogen as the only gas capable to solve in significant quantities in aluminum melt is the main factor influencing gas porosity. Another kind of porosity occurs due to reduction of metal volume due to process of solidification. Fig. 1. show porosity inside aluminum casting (Budic et al., 2009).

During melting of aluminum and its alloys there is a violent reaction between aluminum and the water vapor in the oven atmosphere, according to the following reaction:

$$
2 \mathrm{Al}+3 \mathrm{H}_{2} \mathrm{O} \rightarrow \mathrm{Al}_{2} \mathrm{O}_{3}+3 \mathrm{H}_{2}
$$

Parallel with the aforementioned reaction, another reaction between carbides and aluminum nitrides and water vapor is possible, whereby a certain quantity of gases (methane, $\mathrm{HN}_{3}$, $\mathrm{CO})$ arise.

Penetration of hydrogen into aluminum develops in three process stages: absorption, diffusion, dissolution.

Absorption represents accumulation of gases on the metal surface layer (alloy), from where they enter into interior of the metal by process of diffusion. Gas retained in the interior of the metal in atomic or molecular condition is present in the solution or is incorporated into the metal.

Absorption on contact surface alloy - gas is the first stage of the process in which gas is dissolved into metal. Gas diffuses into metal as consequence of gas solvability at specific temperature. The effect of oxide layer created on the surface of aluminum alloy, which protects it from further oxidation, should be added to the process of absorption.

The quantity of hydrogen which aluminum can take over from water vapor during melting surpasses balance values for dry hydrogen.

Due to reaction of aluminum with water vapor, several times greater gas quantities can pass over to the melt. How much gas will pass over depends upon partial pressure of the water vapor and the speed of chemical reaction. Fig. 2. shows solvability of hydrogen in aluminum alloy (Rapp, 2008).

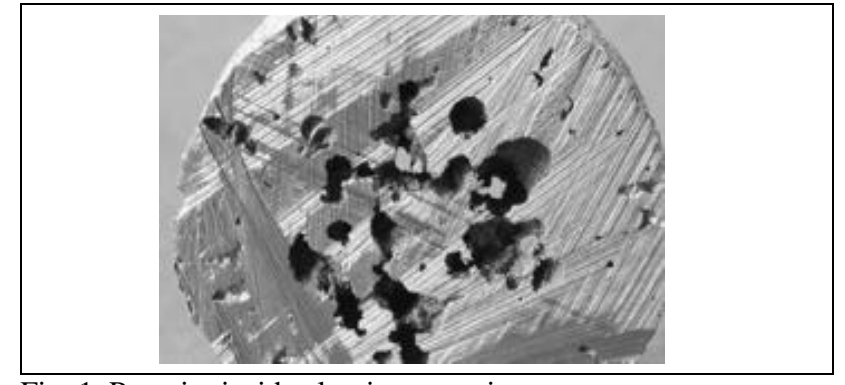

Fig. 1. Porosity inside aluminum casting

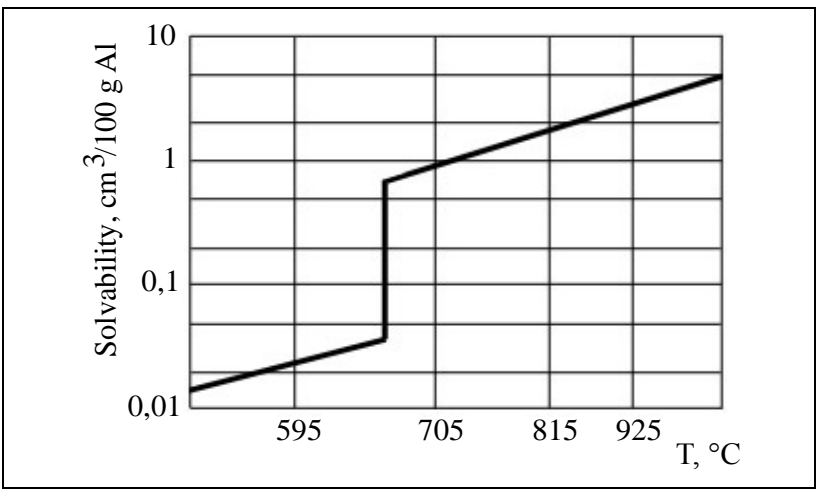

Fig. 2. Solvability of hydrogen in aluminum alloy

\section{EXECUTING OF RESEARCH}

The basic parameters influencing degree of solvability of gases in pure metals and alloys (besides chemical nature of gases and metals) are temperature and pressure. Thereby, we ought not to forget contact time of the melt with gases. Solubility of gases in metals from kinetic point of view is considered as complex of elementary particles. Particles of the gaseous stage in the considered process first collide with the surface of the melt or solid metal. This is accompanied by absorption of gases and dissociation of molecules into atoms.

Testing of the influence of vacuum and pouring temperature on porosity of castings was conducted at laboratory of the Department for Casting of the Faculty of Mechanical Engineering and Naval Architecture in Zagreb. Castings were poured at vacuum of $(30,50$ and $70 \mathrm{~cm} \mathrm{Hg})$, i.e. $(0,39,0,67$ and 0,93 bar). Filling temperature of the molten metal amounted to 650,710 and $770{ }^{\circ} \mathrm{C}$.

The molten aluminum alloy had density of $2900 \mathrm{~kg} / \mathrm{m}^{3}$, and was melted in the electric oven Lindberg CR-5.

The molten metal was filled with the laddle; the filling temperature of the molten metal measured with pyrometer of type HASCO Z251, at temperature of environment of $29^{\circ} \mathrm{C}$.

The examined castings were poured into chill molds in the form of the rumped cone. To enable easier extraction of the casting out of the chill mold, coating with cirkon of type $M$ was applied (made on the base of isopropile alcohol.

After that the chill mold was heated with burner so as to 
remove possibility of creation of gases out of the coating. Subsequently the chill mold was inserted into vacuum chamber, where the casting solidified. It was kept in the vacuum chamber for 2 minutes.

At laboratory for biochemical engineering of the Faculty for Nourishment and Biotechnology in Zagreb mass of the castings was measured. It was done using electronic scales tehtnica ET-1111, which enables precision up to 0,01 g. Each speciment was weighed three times, and the attributed mass of the specimen was the value measured on the scales at least two times. The volume of the castings was measured with the help of the measuration tube. Measurement was conducted by pouring of water into the vessel and measuring of its volume. Afterwards specimen was carefully emerged into the vessel, so as to avoid spraying, i.e. retention of water drops on the walls of the vessel. After emersion of the specimen, the vessel was shaken so as to allow air bubbles, which remained in surface pores of some of castings to come up on the surface. The volume of the specimen was calculated as difference between the final and initial volume of water in the vessel. The goal of this measurement is to calculate the volume of the casting.

\section{RESULTS OF MEASUREMENTS}

Presentation of basic physical sizes of the castings and calculated density of the specimen are shown in Tab. 1. on the basis of the drawn diagrams in Fig. 3 and 4. (Cvjetko, 2009). In diagram in Fig. 3. it can be seen how the increased temperature of the molten metal leads to reduction of the density of the casting. Because specimens (point 1-3) solidified at the same vacuum, these points can be connected with the curve which represents isobars, which simplifies understanding of diagram.

\begin{tabular}{|c|c|c|c|}
\hline & $\begin{array}{c}\text { Vacuum, } \\
\text { bar }\end{array}$ & $\begin{array}{c}\text { Molten temp., } \\
{ }^{\circ} \mathrm{C}\end{array}$ & $\begin{array}{l}\begin{array}{c}\text { Density, } \\
\mathrm{g} / \mathrm{cm}^{3}\end{array} \\
\end{array}$ \\
\hline 1 & \multirow{3}{*}{0,93326} & 770 & 2,0097 \\
\hline 2 & & 710 & 2,0536 \\
\hline 3 & & 650 & 2,1179 \\
\hline 4 & \multirow{3}{*}{0,66667} & 770 & 2,5261 \\
\hline 5 & & 710 & 2,5739 \\
\hline 6 & & 650 & 2,6240 \\
\hline 7 & \multirow{3}{*}{0,3999} & 770 & 2,5373 \\
\hline 8 & & 710 & 2,6014 \\
\hline 9 & & 650 & 2,7085 \\
\hline
\end{tabular}

Tab. 1. Presentation of basic physical sizes of the castings

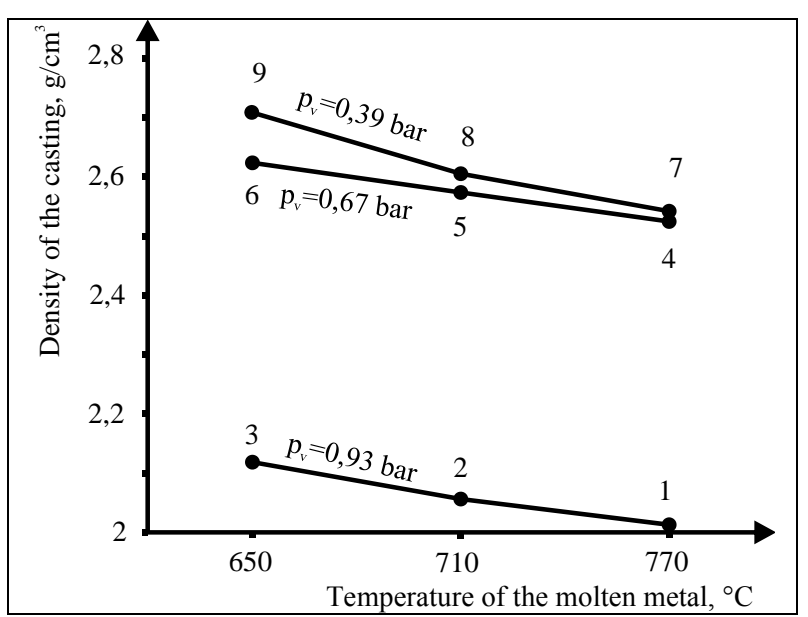

Fig. 3. The influence of temperature of the molten metal on density of the casting for different vacuums

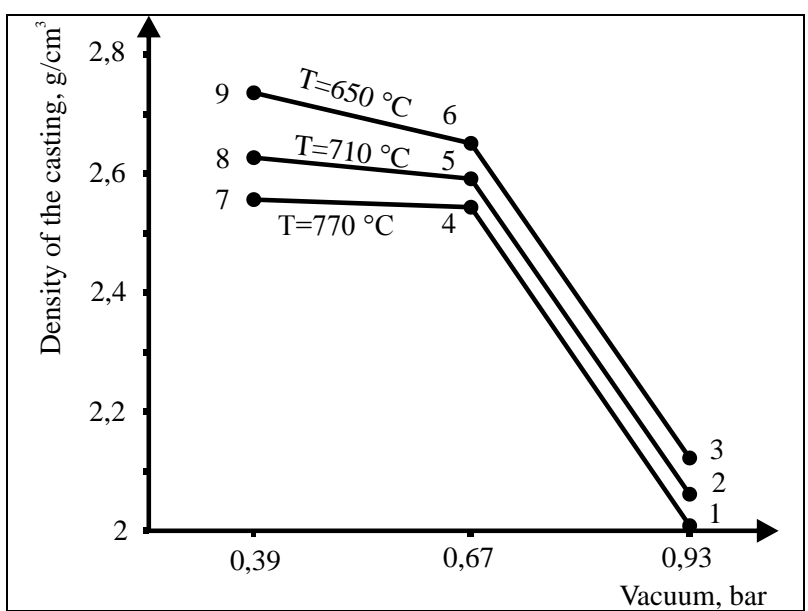

Fig. 4. The influence of vacuum during solidification of molten metal on density of the casting, for different temperatures of the molten metal

In diagram in Fig. 4. it can be seen that the larger volume at solidification causes lesser density of the casting. Because there are three groups each with three castings being solidified at the same vacuums, i.e. being poured at the same temperature, three isobars and three isothermes can be recognized in diagrams.

\section{CONCLUSION}

Gases in castings might appear by mechanical grips during pouring, due to chemical reactions and changes in solvability during process of melting, pouring and formation of the casting. These testing confirmed two earlier mentioned facts that temperature of the molten metal influences density of the casting (temperature increase of the molten metal decrease density of the casting and vice versa) and that the amount of vacuum during solidification affects significantly density of the casting (increased vacuum reduce density of the casting, under precondition that bubbles remained under surface of the casting).

Density of the casting directly indicates porosity of the casting, which results from the known equation for density $(\rho=$ $m / V)$ where $m$ - mass of the casting, and $V$ - volume of the casting.

Porous casting will have smaller mass due to cavities caused by entrapped gas in the molten metal, and according to equation for density, reduction of mass with constant volume causes reduction of density.

In other words, porosity is reversely proportional to density. At higher temperatures of the molten metal and the greater amount of vacuum during process of solidification, castings with increased porosity, i.e. lower density are being obtained.

With castings having greatest density values, no porosity can be observed. Since gas porosity develops due to entrapped dissolve gases in metal, it can be averted by right choice of the casting technology. Because gas bubbles occur as the consequence of precipitation of the dissolved gases in the metal, they can be avoided by regular choice of manufacturing technology of the castings.

\section{REFERENCES}

Budic, I.; Novoselovic, D. \& Gros, J. (2009). Solvability of Hydrogen in Aluminum, Annals of DAAAM for 2009 \& Proceedings of the 20th International DAAAM Symposium, 25-28th November 2009, Vienna, Austria, ISSN 1726-9679, ISBN 978-3-901509-70-4, Katalinic, B. (Ed.), pp. 18051806, Published by DAAAM International Vienna, Vienna

Rapp, R.A. (2008). The Closed-circuit degassing of liquid aluminum by Argon, http://www.springerlink.com 